\title{
Acute and Chronic Toxicity of Selected Cadmium Salts on Earthworm Eisenia andrei under Tropical Conditions
}

\author{
Jayathilake T.A.H.D.G. ${ }^{1}$, Mallawaarachchi M.A.G.D. ${ }^{2}$, De Silva P.M.C.S. ${ }^{2}$ and \\ Peiris L.D.C. ${ }^{* *}$ \\ ${ }^{I}$ Department of Zoology,University of Sri Jayewardenepura, Sri Lanka \\ ${ }^{2}$ Department of Zoology, University of Ruhuna, Sri Lanka \\ *dinithi@sci.sjp.ac.lk
}

\begin{abstract}
Agrochemicals and other hazardous chemicals are well known threats to healthy soil ecosystems. Fertilizers containing cadmium as an impurity are being added extensively to agricultural soils in Sri Lanka. These impurities may have hazardous impacts on soil ecosystems. Therefore toxicity of Cadmium Chloride $\left(\mathrm{CdCl}_{2}\right)$ and Cadmium Sulphate $\left(\mathrm{CdSO}_{4}\right)$ on survival, growth and reproduction of the earthworm Eisenia andrei were investigated under tropical conditions. The standard earthworm toxicity tests were performed according to the guidelines developed by ISO (International Organization for Standardization) and OECD (Organization for Economic Co-Operation and Development). Field collected natural soils were used as the test substrates. The endpoints measured were survival, growth and reproduction together with behavioral effects. Coiling, secretion of mucus and hypersensitivity were noted as common behavioral effects, which was observed in the highest concentrations in both cadmium salts. In terms of survival, both cadmium salts were not toxic to earthworm Eisenia andrei as LC50 were $>1000 \mathrm{mg}$ a.i /Kg dry soil. However, the chronic toxicity of cadmium chloride and cadmium sulphate was extremely high. Biomass reduction and reproduction were severely affected even at lower concentrations. The EC50 value for cadmium chloride and cadmium sulphate was 5.5 (2.6-8.4) $\mathrm{mg}$ a.i $/ \mathrm{kg}$ dry soil and 6.3 (1.411.3) $\mathrm{mg}$ a.i $/ \mathrm{kg}$ dry soil respectively. Lowest observed effect concentration (LOEC) for both salts was $1 \mathrm{mg}$ a.i $/ \mathrm{Kg}$ dry soil and No observed effect concentration (NOEC) was <1 mg a.i /Kg dry soil. Our study concludes that use of high Cd containing fertilizers may risk beneficial soil organisms and application should be done with caution.
\end{abstract}

Keywords: Toxicity, Earthworm, Eisenia, Cadmium

Proceedings of the International Forestry and Environment Symposium 2016, Department of Forestry and Environmental Science, University of Sri Jayewardenepura, Sri Lanka. 